\title{
Evaluation of the Rural Informatization in China under the Background of the Construction of New Socialist Countryside
}

\author{
Yong-Jiang Lei \\ college of economics ,Sichuan Agricultural University \\ 610000 Chengdu, China \\ Cheng-Yi Huang ${ }^{1,2}$ \\ ${ }^{1}$ college of economics,Sichuan Agricultural University \\ 610000 Chengdu, China \\ ahuang66sohu.com \\ ${ }^{2}$ college of information engineering, Sichuan \\ Agricultural University \\ 625000 yaan, China
}

\author{
Cong-Gang Fang \\ Land and resources information center of Chengdu \\ Chengdu, China
}

Ruo-Heng Tian

college of management, Sichuan Agricultural University

Chengdu, China

\begin{abstract}
The paper presents a method (Improved Fuzzy Analytic Hierarchy Process) to evaluate the development of rural informatization over the past decade in China. This article developed a rural informatization evaluation system including Rural informatization infrastructure, Rural informatization technology applications, Rural informatization technology professionals and Rural informatization external environment, four criterion layers and 15 specific indicators. The results show that the overall level of China's rural informatization was gradually increasing but regional development was imbalance, eastern region has the highest level, western region has the lowest level, northeastern is slightly higher than central region. By cluster analysis, found that provinces along the southeast coast and in North China have a better development, in southwest and northwest China have a poor development. At the typical case indicating that in rural informatization development is relatively backward areas, there are also individual cities have a better development.
\end{abstract}

Keywords-Rural informatization; New socialist countryside; Improved Fuzzy Analytic Hierarchy Process; China

\section{INTRODUCTION}

Since entering the $21 \mathrm{st}$ century, we gradually integrated into an information age. Access to information, dissemination of information and application information have more and more influence on our production and life. The combination of information and social production has greatly promoted the social and economic development [1].

The Fifth Plenary Session of the Sixteenth Central Committee of the CPC(Communist Party of China ), in 2005, passed a document (CPC central committee formulate a recommendation about national economic and social development 11th Five-Year Plan) which proposed to the construction of a new socialist countryside as a major historic task of the modernization process, put forward requirements of promoting new socialist countryside and a series of important policies, stated that government will enhance the construction of rural infrastructure and accelerate the construction of rural informatization [2].

\section{A. Related Work}

Scholars for rural informatization problems did a lot of research, literatures focused on the development status of rural informatization, evaluation index system, evaluation methods, and the relationship between rural informatization and socio-economic development. These studies are important for the reference and theoretical basis of this paper. Combining research direction, from the rural informatization evaluation system and evaluation methods to do literature review.

Chinese government proposed a unified National Informatization Index System including 20 indicators [3].Marc U.Porat ,American, proposed a index system named Porat Approach which make use of endogenous growth model of information economics theory, by measuring GNP as a unified benchmark to measure the value-added of information economy sectors[4]. IAP (Information Age Partnership) proposed evaluation system in 2002 , to assess the e-economy system in terms of 4 layers (Environment, Readiness, Uptake and Use, and Impact) [5].

Shi-hong Liu established rural informatization system including six criterion layers and 25 indicators. Who use comprehensive index method analysed China's rural regions development status of informatization [4]. Daoliang Li pointed out that rural informatization construction should include development environment, infrastructure, resources, service system and technology applications [6]. Ling-xian Zhang established rural informatization evaluation system including four criterion layers and 15 indicators. Based on catastrophe theory evaluated Chinese four regional rural informatization level [7]. Yan-hua Song according to the National Informatization Indices programs combined with the practical situation, established Gansu Province's rural informatization evaluation system. [8]. Xu-hui Li established a 
comprehensive evaluation system based on AHP (Analytic Hierarchy Process) and Gray Relational Analysis [9]. Shu Qiao made use of AHP and hierarchical agglomerative clustering method assessed rural informatization Level of Henan Province [10]. Hui Zhao employed factor analysis method researched rural informatization in Ningxia Hui Autonomous Region [11]. Yue-feng Zhou based on fuzzy comprehensive evaluation method estimated rural informatization in three different regions [12]. Yuan-cong Wang adopted multi-index comprehensive method to evaluate agricultural informatization development in Central China [13]. Xi-rui Du evaluated the agricultural informatization in Shangqiu City, based on principal component analysis [14].

Scholars from different aspects designed evaluation systems, and the pros and cons of different evaluation methods of rural informatization were analyzed. Which provide good reference for this paper. In the following several aspects may also conduct in-depth research: scholars mostly using cross-sectional data for a year, and fewer adopt dynamic data to access rural informatization. Many scholars are evaluated against the current situation of rural informatization for a local area or the overall situation of China, but for different regions of China, at different scales, in multi-dimensional have few studies.

\section{MATERIALS AND METHODS}

\section{A. Data Collection}

Data for this paper derived from China Statistical Yearbook which $\quad$ took $\quad$ from
National Bureau of Statistics of the People's Republic of C hina [15].Regional data obtained by adding the total sum of provinces (municipalities) data. The city's (Jiangmen, Mianyang , Luoyang) data come from Bureau of Statistics of each city.

\section{B. Establishment of Index System}

In this paper, the main reference index system are Shihong Liu 's [4], Cheng Yang 's [16], Zhi-wen Huang 's [17] and National Informatization Index System of China [3], combined with the study area to do some amendments. The paper adds specific indicators such as FTTH (Fiber to the Home) rate, rural agro-site visits, number of collegegraduate village officials, rural development of ecommerce etc. Based on the above research, rural informatization evaluation index system was established which includes six criteria layers and 40 specific indicators.

Combined with eight standards of single indicator selection proposed by Dale, to screen the primary evaluation system ( be easily measured; be sensitive; respond to stress; be anticipatory; predict changes; are integrative; have a known responds; how low variability in response) [18]. According to the principles to screen the index system, combined with the actual situation of the data collected, the paper identified the evaluation system of rural informatization, as shown in Table1.

TABLE 1. THE EVALUATION INDEX SYSTEM FOR THE RURAL INFORMATIZATION.

\begin{tabular}{|c|c|c|}
\hline Objective layer & Criterion layer & Index layer \\
\hline \multirow{17}{*}{$\begin{array}{l}\text { Rural } \\
\text { informatization Z }\end{array}$} & $\begin{array}{l}\text { Rural informatization } \\
\text { infrastructureC1(0.4952) }\end{array}$ & Mobile Telephone owned per 100 rural households P1 (unit / one hundred) (0.2335) \\
\hline & & Color TV owned per 100 rural households P2 (set /one hundred) (0.1593) \\
\hline & & Computer owned per 100 rural households P3 (set /one hundred) (0.3735) \\
\hline & & Long-distance optical cable coverage \\
\hline & & $\mathrm{P} 4(\mathrm{~km} / \mathrm{sq} \mathrm{km})(0.0482)$ \\
\hline & & Capacity of Mobile Telephone ExchangesP5 (subscriber/one hundred) (0.0751) \\
\hline & & Broad Band Subscribers Port of Internet \\
\hline & & P6 (subscriber/one hundred ) (0.1104) \\
\hline & $\begin{array}{l}\text { Rural informatization } \\
\text { technology applications } \\
\text { C2 }(0.2670)\end{array}$ & The proportion of Internet users in rural areas P7 (\%) $(0.75)$ \\
\hline & & Percentage of administrative village with posts $\mathrm{P} 8(\%)(0.25)$ \\
\hline & $\begin{array}{l}\text { Rural informatization } \\
\text { technology } \\
\text { professionalsC3(0.0837) }\end{array}$ & $\begin{array}{l}\text { Percentage of Transmission, Computer Service and Software employment of total employment P9(\%) } \\
\text { () }(0.75)\end{array}$ \\
\hline & & $\begin{array}{l}\text { Number of Teachers and Staff in Secondary Vocational Schools P10(person /ten thousand persons) } \\
(0.25)\end{array}$ \\
\hline & $\begin{array}{r}\text { informatization } \\
\text { environment }\end{array}$ & Percentage of college and above education population of the total number P11(\%) $(0.0613)$ \\
\hline & & The proportion of telecom investment in total investment $\mathrm{P} 12(\%)(0.2505)$ \\
\hline & & GDP per capita P13 (Ten thousand Yuan RMB / capita) (0.4252) \\
\hline & & Urbanization rate $\mathrm{P} 14(\%)(0.1025)$ \\
\hline & & Consumption expenditure of rural households on education and telecommunication P15(\%) (0.1605) \\
\hline
\end{tabular}




\section{Formulas}

Improved FAHP (Fuzzy Analytic Hierarchy Process) used in this paper. Compared to traditional hierarchical analysis method, use three priority scale method to establish judgment matrix is simple, easy and more in line with people's logical thinking habits. The established fuzzy consistent matrix requires fewer iterations in the actuarial process and faster convergence, but also meet the accuracy requirement [19].The calculation method:

$$
\text { Three scale method }\left\{\begin{array}{cl}
0 & \text { A is worse than } B \\
0.5 & \text { A and B are equal } \\
1 & \text { A is better than B }
\end{array}\right.
$$

Use (1) to establish complementary fuzzy judge matrix $\mathrm{F}=\left(\mathrm{f}_{\mathrm{ij}}\right)_{\mathrm{n} \times \mathrm{n}}$ which is named priority judge matrix.

$$
r_{i}=\sum_{j=1}^{n} f_{i j}
$$

Use formula (2) to summate the row of the judge matrix.

$$
r_{i j}=\frac{r_{i}-r_{j}}{2 n}+0.5
$$

Using the formula (3) to convert fuzzy judge matrix $\mathrm{F}=\left(\mathrm{f}_{\mathrm{ij}}\right)_{\mathrm{n} \times \mathrm{n}}$ to $\mathrm{R}=\left(\mathrm{r}_{\mathrm{ij}}\right)_{\mathrm{n} \times \mathrm{n}}$

$$
W^{(0)}=\left[\frac{\sum_{j=1}^{n} e_{1 j}}{\sum_{i=1}^{n} \sum_{j=1}^{n} e_{i j}}, \frac{\sum_{j=2}^{n} e_{2 j}}{\sum_{i=1}^{n} \sum_{j=1}^{n} e_{i j}}, \cdots \frac{\sum_{j=n}^{n} e_{n j}}{\sum_{i=1}^{n} \sum_{j=1}^{n} e_{i j}}\right]^{T}
$$

Using the formula (4) to seek the vector $\mathrm{W}^{(0)}=$ $\left(\mathrm{w}_{1}, \mathrm{w}_{2}, \ldots, \mathrm{w}_{\mathrm{n}}\right)^{\mathrm{T}}$.

$$
e_{i j}=\frac{r_{i j}}{r_{j i}}
$$

Using the formula (5) to convert the complementary judgment matrix $R=\left(r_{i j}\right)_{n \times n}$ to reciprocal judgment matrix $E=\left(e_{i j}\right)_{n \times n}$.

$$
\mathrm{V}_{\mathrm{k}+1}=\mathrm{E} \times \mathrm{V}_{\mathrm{k}}
$$

With $\mathrm{V}^{(0)}=\left(\mathrm{w}_{1}, \mathrm{w}_{2}, \ldots, \mathrm{w}_{\mathrm{n}}\right)^{\mathrm{T}}$ is the iteration initial value, using iterative formula (6) seeking eigenvectors $V_{k+1}$ and $V_{k+1}$ 's infinity norm of $\left\|V_{k+1}\right\|_{\infty}$.

$$
\mathrm{V}_{\mathrm{k}}=\mathrm{V}_{\mathrm{k}+1} /\left\|\mathrm{V}_{\mathrm{k}+1}\right\|_{\infty}
$$

The formula (7) as new initial value to iterate Until

$$
\left\|\mathrm{V}_{\mathrm{k}+1}\right\|_{\infty}-\left\|\mathrm{V}_{\mathrm{k}}\right\|_{\infty}<\varepsilon
$$

iteration stops, $\mathrm{V}_{\mathrm{k}+1}$ will be normalized, the resulting vector is sorted vector [19], [20].

According to the relevant research on rural informatization index system and index weights. Combined with the actual situation in China, based on Improved FAHP. The weight of rural informatization evaluation system for each index can be obtained by compiled programs (using Stata11.2) [19], as shown in Table 1.

\section{RESULTS}

With the development of Chinese society and economy and polices constructing the new socialist countryside implemented. From 2005 to 2014, the overall level of information technology in rural China increased year by year. National averages rural informatization index rose from 21.21 to 59.21 , an increase of $35.82 \%$.

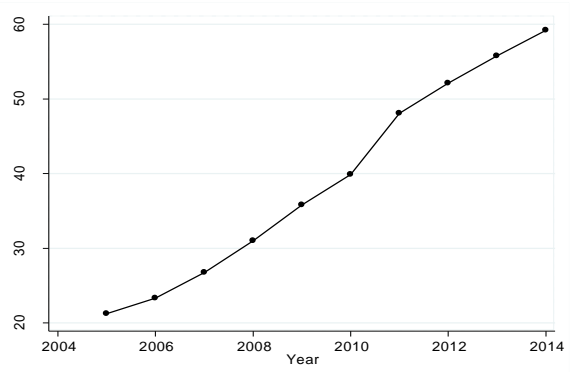

Figure 1. The national average rural informatization development of china.

\section{A. The Regional Scale}

According to the situation of China's economic and social development, China is divided into four economic regions: eastern, northeastern, central and western regions. (1) Northeastern region (Heilongjiang, Jilin, Liaoning, eastern Inner Mongolia (Hulun Buir City, Xing'an League, Tongliao, Chifeng City, Xilin Gol League ) ) (2) Central region (Shanxi, Henan, Hubei, Hunan, Jiangxi, Anhui) (3) Eastern region (Beijing, Tianjin, Hebei, Shandong, Jiangsu,

\begin{tabular}{|c|c|c|c|c|c|c|c|c|c|c|}
\hline Region & 2005 & 2006 & 2007 & 2008 & 2009 & 2010 & 2011 & 2012 & 2013 & 2014 \\
\hline Central & 20.75 & 23.19 & 27.19 & 30.45 & 34.20 & 37.74 & 46.54 & 49.24 & 51.79 & 54.00 \\
\hline North-eastern & 25.26 & 26.85 & 30.09 & 33.81 & 38.29 & 41.26 & 48.63 & 51.07 & 53.20 & 56.08 \\
\hline Eastern & 32.33 & 34.53 & 41.31 & 44.82 & 49.29 & 52.68 & 59.32 & 62.56 & 64.95 & 66.89 \\
\hline Western & 15.74 & 17.70 & 21.63 & 25.46 & 29.65 & 33.23 & 43.40 & 46.49 & 49.41 & 52.01 \\
\hline
\end{tabular}
Shanghai, Zhejiang, Fujian, Guangdong, Hainan) (4) Western region (Chongqing, Sichuan, Guangxi, Guizhou, Yunnan, Shaanxi, Gansu, western Inner Mongolia Autonomous Region, Ningxia Hui Autonomous Region, Xinjiang Uygur Autonomous Region, Qinghai, Tibet Autonomous Region).

TABLE 2. RURAL INFORMATIZATION COMPOSITE INDEX IN CHINESE FOUR REGIONS OVER THE PAST DECADE. 
As can be seen from Table 2, the rural informatization development of China's four regions reflects the overall upward trend, but there is a big gap between regions. The rural informatization level: the eastern region has the highest level, the western region has the lowest level, northeastern is slightly higher than the central region.

It is worth noting that, although, the overall level of western region rural informatization is the lowest, but in 2005-2014 year, its rural informatization development speed is growing fastest in the four regions. These developments, to some extent ,due to The great western development strategy and a series of policies implemented by Chinese government to improve rural infrastructure, the most typical is "Extending Radio and TV Broadcasting
Coverage to Every Village Project" and the project of "Uniting Television, Computer and Telephone as one". Implementation of these projects has greatly promoted the construction of rural infrastructure in western region, the backward situation of rural informatization in western also improved.

\section{B. The Provincial Scale}

Through the analysis of China's 31 provinces of rural informatization-related data, 2005-2014, based on Improved FAHP to determine the weight of the index system, calculated annually provinces rural informatization index in Table 3 . The respective provincial administrative units also have different degrees of growth.

TABLE 3. RURAL INFORMATIZATION COMPOSITE INDEX IN CHINA OVER THE PAST DECADE.

\begin{tabular}{|c|c|c|c|c|c|c|c|c|c|c|}
\hline Area & 2005 & 2006 & 2007 & 2008 & 2009 & 2010 & 2011 & 2012 & 2013 & 2014 \\
\hline National & 21.21 & 23.32 & 26.75 & 30.99 & 35.81 & 39.88 & 48.08 & 52.12 & 55.76 & 59.21 \\
\hline Bejing & 45.50 & 47.90 & 58.42 & 63.35 & 68.30 & 70.44 & 73.17 & 74.91 & 76.37 & 77.51 \\
\hline Tianjin & 32.74 & 34.65 & 38.80 & 42.02 & 44.52 & 46.53 & 56.85 & 59.39 & 61.54 & 59.60 \\
\hline Hebei & 25.35 & 26.91 & 27.38 & 29.91 & 34.31 & 38.50 & 52.20 & 55.77 & 58.04 & 60.39 \\
\hline Shanxi & 21.44 & 26.28 & 27.29 & 29.96 & 35.05 & 37.13 & 48.66 & 51.95 & 55.33 & 56.99 \\
\hline Inner Mongolia & 14.50 & 16.42 & 23.90 & 27.33 & 33.11 & 34.94 & 46.83 & 50.28 & 52.64 & 52.57 \\
\hline Liaoning & 28.17 & 30.07 & 29.37 & 32.96 & 36.78 & 40.25 & 46.99 & 49.20 & 51.33 & 53.78 \\
\hline Jilin & 22.83 & 24.38 & 30.86 & 34.42 & 40.25 & 42.49 & 51.11 & 54.47 & 57.06 & 59.69 \\
\hline Heilong-jiang & 24.79 & 26.11 & 30.05 & 34.07 & 37.85 & 41.02 & 47.78 & 49.54 & 51.22 & 54.76 \\
\hline Shanghai & 48.31 & 50.35 & 58.43 & 62.64 & 69.14 & 70.48 & 66.86 & 70.17 & 70.68 & 72.65 \\
\hline Jiangsu & 29.11 & 33.27 & 41.21 & 40.24 & 43.81 & 49.24 & 56.52 & 61.42 & 65.88 & 70.29 \\
\hline Zhejiang & 36.11 & 38.73 & 48.66 & 53.32 & 57.44 & 60.95 & 64.65 & 68.04 & 71.11 & 73.57 \\
\hline Anhui & 23.45 & 25.21 & 26.46 & 30.82 & 33.58 & 39.28 & 43.94 & 47.01 & 49.37 & 51.57 \\
\hline Fujian & 29.84 & 31.82 & 40.86 & 45.51 & 50.17 & 54.91 & 63.17 & 67.22 & 69.51 & 72.01 \\
\hline Jiangxi & 22.59 & 24.35 & 28.67 & 31.30 & 35.57 & 37.69 & 45.86 & 48.47 & 50.96 & 53.25 \\
\hline Shandong & 27.03 & 28.49 & 30.99 & 36.66 & 41.26 & 45.37 & 50.59 & 54.01 & 57.20 & 60.35 \\
\hline Henan & 20.78 & 22.35 & 29.47 & 32.72 & 35.45 & 39.96 & 47.57 & 48.88 & 50.14 & 52.07 \\
\hline Hubei & 19.95 & 22.53 & 29.53 & 32.69 & 36.45 & 40.24 & 49.54 & 52.91 & 55.73 & 58.81 \\
\hline Hunan & 16.26 & 18.43 & 21.76 & 25.23 & 29.11 & 32.12 & 43.69 & 46.20 & 49.23 & 51.33 \\
\hline Guang-dong & 31.81 & 33.21 & 43.19 & 46.36 & 51.33 & 53.83 & 62.06 & 64.08 & 65.54 & 66.68 \\
\hline Guangxi & 18.34 & 20.35 & 24.73 & 27.91 & 32.88 & 35.95 & 46.82 & 49.08 & 51.21 & 52.81 \\
\hline Hainan & 17.54 & 19.98 & 25.21 & 28.15 & 32.64 & 36.57 & 47.14 & 50.57 & 53.58 & 55.87 \\
\hline $\begin{array}{l}\text { Chong- } \\
\text { qing }\end{array}$ & 19.04 & 21.32 & 25.59 & 29.50 & 31.54 & 36.30 & 45.37 & 49.33 & 51.90 & 54.46 \\
\hline Sichuan & 16.05 & 18.44 & 23.27 & 27.71 & 32.08 & 34.81 & 42.28 & 45.67 & 48.54 & 50.88 \\
\hline Guizhou & 10.33 & 12.11 & 14.71 & 18.03 & 21.95 & 26.49 & 36.39 & 40.47 & 44.46 & 47.72 \\
\hline Yunnan & 12.52 & 14.72 & 21.03 & 25.21 & 29.30 & 34.12 & 42.59 & 44.86 & 48.06 & 49.68 \\
\hline Tibet & 7.41 & 9.05 & 8.80 & 10.60 & 13.97 & 16.18 & 28.85 & 31.86 & 34.48 & 38.92 \\
\hline Shaanxi & 20.12 & 21.99 & 28.35 & 32.23 & 36.10 & 40.43 & 50.59 & 53.46 & 55.81 & 58.04 \\
\hline Gansu & 17.45 & 19.06 & 19.88 & 23.04 & 26.78 & 30.01 & 39.21 & 42.32 & 45.58 & 48.34 \\
\hline Qinghai & 13.75 & 15.95 & 20.28 & 25.47 & 30.01 & 34.12 & 47.57 & 50.33 & 53.26 & 55.38 \\
\hline Ningxia & 25.36 & 26.81 & 30.93 & 36.99 & 42.10 & 45.76 & 53.72 & 56.86 & 59.56 & 64.67 \\
\hline Xinjiang & 14.00 & 16.19 & 18.11 & 21.47 & 25.96 & 29.62 & 40.63 & 43.33 & 47.41 & 50.63 \\
\hline
\end{tabular}


After the analysis of China's provincial informatization index, 2004-2015, combined with Ward's Method to do cluster analysis. Through cluster analysis dendrogram and the actual situation of informatization development in rural China. The rural informatization development in China can be divided into three categories. Levell:the development of rural informatization is better, a higher degree of informatization; Level 2:the degree of rural informatization development is in general, at an intermediate level; Level 3:those areas of information technology development is still at a low level, there is a large space for the rural informatization development.

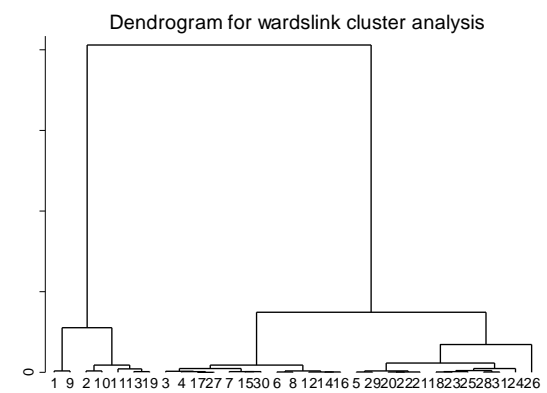

Figure 2. Dendrogram for index cluster analysis

From Table 4 we can see the rural informatization development of three cities, in which Jiangmen City has a better development, Mianyang City in an intermediate position, Luoyang City has a relatively low level of informatization. Mianyang City, which rural informatization infrastructure index is highest in three cities, Jiangmen City, which rural informatization technology applications index is highest. It is noteworthy that Mianyang City, which is belong to western region (economic geography partition) and Level 3 region; while Luoyang city, which is belong to central and Level2 region. This shows that in rural informatization development more backward areas exist better individual cities.

\section{DISCUSSION AND CONCLUSIONS}

This article shows that China rural informatization level is gradually increasing over the past decade. But the overall level is not high, while regional differences are significant. Southeast coastal areas and North China have a higher level of development, southwest and northwest China have a lower level of development. As can be seen from the research, rural informatization development and economic development are closely related (regions with a better economic conditions are more likely to have a higher level of rural informatization). China implemented a series of policies, such as "Extending Radio and TV Broadcasting Coverage to Every Village Project" and the project of "Uniting Television, Computer and Telephone as one" promoting the development of rural informatization infrastructure and rural informatization
Level1 region: Beijing, Shanghai, Tianjin, Jiangsu, Zhejiang, Fujian, Guangdong; Level2 region: Hebei, Shanxi, Hubei, Shaanxi, Liaoning, Heilongjiang, Anhui, Jiangxi, Henan, Jilin, Shandong, Ningxia; Level3 region: Inner Mongolia, Qinghai, Guangxi, Chongqing, Hainan, Hunan, Sichuan, Yunnan, Gansu, Xinjiang, Guizhou, Tibet. From the geographic distribution can be seen, Level1 regions are mainly distributed in the southeast coastal areas as well as Beijing, Tianjin; Level2 regions are mainly distributed in central China, North China, northeast China; Level3 regions are mainly distributed in the southwest and northwest.

\section{The Typical Case of the City Scale}

According to results of the cluster analysis, this paper selected representative cities in three regions to do microlevel analysis. Jiangmen City, Guangdong Province, which is national informatization pilot city; Luoyang City, Henan Province, which is national new urbanization comprehensive pilot city ;Mianyang City, Sichuan Province, which is the first "Uniting Television, Computer and Telephone as one" pilot city are selected.

technology applications in backward rural areas, improved the overall level of rural informatization.

Some new indicators, although, such as the application of agricultural science and technology Internet system and e-commerce development in rural areas, for existing rural informatization evaluation system is an innovation, due to difficulties in data collection which can not be reflected in the evaluation system. In the future, when the conditions are ripe we can put these indicators into the evaluation system.

Through this study, Three scales of rural informatization development is evaluated based on Improved FAHP, the index system is better reflected rural informatization development situation in different hierarchy areas ,which also in line with the actual situation in China. The current synthetic evaluation methods mainly are comprehensive index method, AHP, principal component analysis, data envelopment analysis, gray relation analysis, neural network evaluation method, etc. This article requires a combination of decade of data in three dimensions to do comprehensive evaluation, in the case of this article, Improved FAHP evaluation method is more suitable than the other. In the future comprehensive evaluation, combination evaluation model should be built by a variety of evaluation methods. Which can eliminate the errors caused by single evaluation method. In the index system's weight aspect, the combination of subjective and objective weight determination method should be stressed, which can overcome the limitations of single weight determination method. 
TABLE 4. RURAL INFORMATIZATION COMPOSITE INDEX IN THREE CITIES

\begin{tabular}{llllll}
\hline Area & $\begin{array}{l}\text { Infras- } \\
\text { tructure }\end{array}$ & $\begin{array}{l}\text { Technology } \\
\text { application }\end{array}$ & Professional & $\begin{array}{l}\text { External } \\
\text { environment }\end{array}$ & $\begin{array}{l}\text { Comprehensive } \\
\text { index }\end{array}$ \\
\hline Jiangmen & 45.01787 & 14.61821 & 0.150822 & 0.309316 & 60.09621 \\
Mianyang & 50.12188 & 3.356948 & 0.084984 & 0.22385 & 53.78766 \\
Luoyang & 35.10766 & 12.64622 & 0.150665 & 0.326645 & 48.23119 \\
\hline
\end{tabular}

\section{ACKNOWLEDGMENTS}

This research was supported by the Special application foundation of Sichuan Province (Grant No.2015JY0059) and Social sciences special research funds of Sichuan Agricultural University (2014).

\section{REFERENCES}

[1] Jin Xu: Analysis of Impacts of Regional Informatization on Economic Growth. J. Statistical Research. 27,74-80 (2010) (in Chinese)

[2] Bing-kun Li: Solid and steady Promote the construction of new socialist countryside. J. Chinese Rural Economy.11, 4-9 (2005) (in Chinese)

[3] China's information industry network, http://www.cnii.com.cn/20021111/ca103215.htm

[4] Shi-hong Liu: Study on Evaluation/Measurement Method for China's Rural Informatization. J. Scientia Agricultura Sinica. 41(4), 1012-1022 (2008) (in Chinese)

[5] Booz Allen Hamilton Inc.: International e-Economy Benchmarking The World's Most Effective Policies For The e-Economy. London (2002)

[6] Dao-liang Li: China Rural Informatization Development Report. J. China Information Times 72-84 (2008) (in Chinese)

[7] Ling-xian Zhang: Evaluation of the rural informatization level in four Chinese regions: A methodology based on catastrophe theory. J. Mathematical and Computer Modelling. 58, 868-876 (2013)

[8] Yan-hua Song: Research on the developing level of Gansu Rural Information and countermeasures. J. Gansu Science and Technology.27(21),7-9 (2011) (in Chinese)

[9] Xu-Hui Li: Research on the Evaluation of Rural Informatization Level Based on Gray Relational Analysis Method. J. Journal of
Jilin Business and Technology College .31(1), 81-85(2014) (in Chinese)

[10] Shu Qiao: Study on Rural Informatization Level of Henan Province. J. Chinese Agricultural Science Bulletin. 25(23), 460463(2009) (in Chinese)

[11] Hui Zhao: Analysis on the Development of Ningxia Rural Informatization Based on Factor Analysis. J. Journal of Anhui Agricultural Sciences .38(13), 6995-6996 (2010) (in Chinese)

[12] Yue-feng Zhou: Research on Rural Informatization Index System Based on Fuzzy Comprehensive Evaluation. J. Rural Economy and Science .251,20-22 (2010) (in Chinese)

[13] Yuan-cong Wang: Evaluation of development of agricultural modernization in central China. In: 2013 International Conference on Electronic Engineering and Computer Science, IERI Procedia. 4, 417 - 424 , Shanghai (2013)

[14] Xi-rui Du: Evaluation research Based on principal component analysis of agricultural informatization level. J. Agriculture of Henan. 3, 55-56 (2014) (in Chinese)

[15] National Bureau of Statistics of the People's Republic of China, http://www.stats.gov.cn

[16] Cheng Yang: Constructs the Evaluating Indicator System for China's Countryside Informationization. J. Journal of Intelligence 2, 24-27 (2009) (in Chinese).

[17] Zhi-wen Huang: Study on Analysis Evalution for China's Rural Informatization In Six Provinces of the Central. J. Modern Agricultural Sciences and Technology .15,370-374 (2009) (in Chinese)

[18] Dale V. H. Beyeler S. C.: Challenges in the development and use of ecological indicators. Ecological Indicators .1(1), 3-10. (2001)

[19] Duan-lian Peng: Construction of Performance Index System and Performance Measurement on Social insurance of Local Government. J. Journal of Central University of Finance \& Economics. 1, 19-26 (2015) (in Chinese)

[20] Yong Li: An improved fuzzy AHP method. J. Journal of Northwest University (Natural Science Edition). 35,11-12 (2005) (in Chinese) 